\title{
RECENT TRENDS IN NEONATAL MORTALITY IN VERY LOW BIRTH WEIGHT KOREAN INFANTS: IN COMPARISON WITH JAPAN AND THE USA
}

\author{
W.-H. Hahn, J.-Y. Chang, K.S. Shim, C.-W. Bae \\ Pediatrics, School of Medicine, Kyung Hee University, Seoul, Republic of Korea
}

With regard to the outcome of intensive neonatal care, one of the most important concerns in neonatology is the mortality rate of very low birth weight infants (VLBWI; birth weight $<1,500 \mathrm{~g}$ ) and extremely low birth weight infants (ELBWI; birth weight $<1,000 \mathrm{~g}$ ). The present study was conducted to analyze and compare the mortality of VLBWI and ELBWI and neonatal care among Korean, Japanese, and American newborns. In Korea, the survival rates of VLBWI have increased significantly; they were $31.8 \%$ in the early $1960 \mathrm{~s}$, $65.8 \%$ in the early $1990 \mathrm{~s}, 77.5 \%$ in $2002,84.7 \%$ in 2007 , and $85.7 \%$ in 2009 . The survival rates of ELBWI have also increased; they were $8.2 \%$ in the early $1960 \mathrm{~s}, 37.4 \%$ in the early $1990 \mathrm{~s}, 56.1 \%$ in $2002,67.7 \%$ in 2007 , and $71.8 \%$ in 2009 . The survival rates of VLBWI and ELBWI have significantly improved over the past $50 \mathrm{yr}$ in Korea. However, the Korean survival rates of VLBWI and ELBWI are still lower than for similar groups in Japan and the USA. To achieve better outcomes that reach the level of these countries, the organization of perinatal care centers, nationwide neonatal perinatal research networks, and regionalization are needed in Korea. 